\title{
OJS OPEN

\section{PRÁTICAS DOCENTES NO ENSINO BÁSICO DE GEOGRAFIA EM LONDRINA/PR: UM ESTUDO DE CASO}

\author{
Guilherme Pereira Cocato ${ }^{1}$, Douglas Vitto ${ }^{2}$, Ricardo Lopes Fonseca ${ }^{3}$ \\ ${ }^{1}$ Mestrando em Geografia na Universidade Estadual Paulista (FCT/UNESP), câmpus de Presidente Prudente-SP. \\ Licenciatura, bacharelado e especialização em ensino de Geografia pela Universidade Estadual de Londrina (UEL). E- \\ mail: guilherme_pereira@yahoo.com.br, Orcid: http://orcid.org/0000-0003-4462-8177 \\ ${ }^{2}$ Mestrando em Geografia na Universidade Estadual de Londrina (UEL). Licenciatura e especialização em Ensino de \\ Geografia pela Universidade Estadual de Londrina(UEL),E-mail: d_vitto@hotmail.com,Orcid: http://orcid.org/0000- \\ 0002-9731-8343 \\ ${ }^{3}$ Professor Adjunto do Departamento de Geociências da Universidade Estadual de Londrina (UEL), Doutor e mestre em \\ Geografia pela Universidade Estadual de Londrina (UEL), Licenciatura em Geografia pela Universidade Estadual de \\ Maringá (UEM), E-mail: ricardolopesfonseca@hotmail.com, Orcid: http://orcid.org/0000-0002-2077-2476
}

Artigo recebido em 21/12/2020 e aceito em 24/06/2021

\section{RESUMO}

O presente artigo foi elaborado a partir de observações acerca das práticas de ensino de Geografia no Colégio Estadual Barão do Rio Branco e Colégio Estadual Vicente Rijo, em Londrina/PR, no ano de 2015. No contexto de uma sociedade globalizada, o objetivo é realizar reflexões epistemológicas acerca das influências dos ensinos tradicional e crítico nos ambientes da Geografia escolar, e a relação destas com a Geografia acadêmica. A metodologia de cunho qualitativo consistiu na participação dos pesquisadores na postura de "observador total" durante 11 dias, no ensino fundamental e médio, registrando em caderneta as metodologias e atividades propostas pelos professores. Os resultados foram representados por meio de um mapa conceitual e posteriormente analisados. E, enquanto proposta, esta pesquisa tem como ponto forte o debate sobre possíveis caminhos teórico-metodológicos a serem trilhados nas práticas educacionais geográficas, assim como os desafios para que docentes da área, em formação ou formados, se fortaleçam em sua atuação na rede escolar. A partir do destaque dado a estas questões, almeja-se alcançar uma Geografia plural para além do ambiente acadêmico - também na Geografia escolar - essencialmente por meio de uma formação abrangente e continuada.

Palavras-chave: Ensino de Geografia; Formação Continuada; Epistemologia Geográfica. 


\title{
TEACHING PRACTICES IN GEOGRAPHY BASIC EDUCATION IN LONDRINA / PR: A CASE STUDY
}

\begin{abstract}
This article was elaborated from observations about Geography teaching practices at Colégio Estadual Barão do Rio Branco and Colégio Estadual Vicente Rijo, in Londrina/PR, in 2015. In the context of a globalized society, the objective is to induce epistemological reflections on the influences of traditional and critical teaching in School Geography spaces, and their relationship with Academic Geography. The qualitative research method consisted of the participation of researchers in the posture of "total observer" for 11 days, in elementary and high school, recording in booklets the methodologies and activities proposed by the teachers. The results were represented using a conceptual map and later analyzed. And, as a proposal, this research has as its strong point the debate on possible theoretical and methodological paths to be followed in geographic educational practices, as well as the challenges for teachers in the area, in training or graduates, to strengthen themselves in their performance in the school network. Based on the emphasis given to these issues, the aim is to achieve plural geography beyond the academic environment - also in school geography - essentially through comprehensive and continuous training.
\end{abstract}

Keywords: Geography Teaching. Continuing Education. Geographic Epistemology.

\section{PRÁCTICAS DIDÁCTICAS EN GEOGRAFÍA EDUCACIÓN BÁSICA EN LONDRINA / PR: UN ESTUDIO DE CASO}

\begin{abstract}
RESUMEN
Este artículo se elaboró a partir de observaciones sobre las prácticas de enseñanza de la Geografía en el Colégio Estadual Barão do Rio Branco y el Colégio Estadual Vicente Rijo, en Londrina / PR, en 2015. En el contexto de una sociedad globalizada, el objetivo es realizar reflexiones epistemológicas sobre las influencias de la enseñanza tradicional y crítica en los entornos de la Geografía escolar, y su relación con la Geografía académica. La metodología cualitativa consistió en la participación de investigadores en la posición de "observador total" durante 11 días, en primaria y secundaria, registrando en cuadernillo las metodologías y actividades propuestas por los docentes. Los resultados fueron representados mediante un mapa conceptual y posteriormente analizados. Y, como propuesta, esta investigación tiene como punto fuerte el debate sobre los posibles caminos teóricos y metodológicos a seguir en las prácticas educativas geográficas, así como los desafíos de los docentes del área, en formación o egresados, para fortalecerse en su desempeño en la red escolar. Partiendo del énfasis que se le da a estos temas, se busca lograr una geografía plural más allá del ámbito académico - también en la geografía escolar - esencialmente a través de una formación integral y continua.
\end{abstract}

Palabras-clave: Enseñanza de la Geografía. Educación continua. Epistemología Geográfica. 


\section{INTRODUÇÃO}

Em um momento em que se faz importante autenticar a sala de aula como espaço de reflexões e reivindicações constantes do direito político e civil, além da autonomia e da justiça social é necessário assumir a responsabilidade de fazer a Geografia escolar uma possibilidade para a formação da cidadania, atribuindo a ela sua identidade que não desvanece de uma dimensão ideológica e política.

A importância do estágio obrigatório dentro da formação de docentes é incontestável, sendo este processo passível de diversas observações, experiências e contato com o ambiente de ensino, com suas particularidades e com o que, possivelmente, pode ser melhorado na prática pedagógica. Como já afirmou Santos (2013), a pesquisa proveniente das experiências em estágios permite identificar os êxitos e falhas teóricas e metodológicas que permeiam a prática docente, além de compreender a dinâmica cotidiana da sala de aula, para que os futuros professores, durante o seu processo formativo, possam refletir acerca de possíveis lacunas para serem supridas e inovações necessárias, a fim de melhorar a interação entre a teoria e a prática considerando a realidade da atual sociedade e dos estudantes.

O presente artigo objetiva realizar reflexões acerca das influências de práticas educacionais tradicionais e críticas nos espaços pedagógicos do ensino de Geografia, observados nos colégios estaduais Barão do Rio Branco e Vicente Rijo, durante o estágio da disciplina de Ensino de Geografia e Estágio de Vivência Docente, da graduação do curso de Geografia da Universidade Estadual de Londrina no ano de 2015. Além de analisar alguns desafios e possibilidades da formação docente no mundo contemporâneo.

A partir de uma visão simplificada, a escola pode ser considerada o lócus da prática e a universidade o lócus da teoria. Mas, conforme Santos (2013) afirma, a prática profissional da docência exige uma fundamentação teórica sólida. Como unidade, teoria e prática andam juntas, sendo relacionadas em uma relação de influências simultâneas, em que a prática é refinada pela teoria e a teoria é retrabalhada a partir do conhecimento adquirido na realidade concreta. Ou seja, é fundamental a interação entre teoria e prática na ação docente junto aos estudantes.

Porém, por meio das atividades práticas do ensino de Geografia nas instituições em que as observações foram realizadas, verifica-se a presença notória do ensino tradicional. Tal influência nos leva a refletir acerca do caminhar simultâneo entre a Geografia escolar e a Geografia acadêmica, e o aparente distanciamento existente entre elas.

Nesse sentido, propõe-se um resgate teórico de importantes autores para a questão, no âmbito do que poderia se chamar aplicação ideal da licenciatura. Paralelamente, procura-se validar estas 
práticas por meio de observações em sala de aula, a fim de averiguar a realidade destas propostas holísticas/críticas. Por fim, exploram-se alternativas ao contexto vivido, trazendo à tona conceitos que não inéditos, mas que atualmente são mais urgentes do que nunca.

\section{BREVES PONTUAÇÕES DA TRAJETÓRIA DA GEOGRAFIA E SEU ENSINO NO BRASIL}

Para um melhor entendimento da evolução histórica da Ciência Geográfica, desde antes de sua sistematização, passando por suas diversas correntes que se sucederam de acordo com os períodos históricos, até o intenso debate epistemológico que hoje ocorre acerca de qual abordagem melhor se insere no ensino público das escolas tradicionais (em comparação com a abordagem que realmente é feita), é necessário que se faça uma retomada desse processo histórico e que sejam pontuados alguns aspectos principais.

O ensino tradicional em Geografia imperou no Brasil praticamente desde a implantação dessa área do conhecimento enquanto disciplina institucionalizada. Segundo Melo, Vlach e Sampaio (2007), a origem da escola tradicional remete ao fortalecimento do estado prussiano perante a formação do Estado alemão e na guerra franco-prussiana de 1870, com o objetivo de criar uma identidade nacional e formar novos trabalhadores de certa forma já treinados e "domesticados" para cada função que fosse necessária, por meio de um ensino padronizado que controlasse as massas.

Este modelo de ensino se espalhou rapidamente, sendo exportado para países capitalistas que desejavam que as próximas gerações de operários já crescessem sendo preparados para o trabalho, perpetuando assim o modo de produção e dominação vigente. A adoração à imagem da pátria acompanhava este meio e a Geografia se insere neste contexto ao servir como instrumento para os interesses de expansão territorial e ideológica dos grandes poderes nacionais e econômicos.

Costa e Rocha (2010) afirmam que a organização sistematizada da Geografia possui raízes filosóficas desde o século XVII, em autores como Descartes (1596 - 1650), Kant (1724 - 1804), Darwin (1809 - 1882), Comte (1789 - 1857), Hegel (1770 - 1831) e Marx (1818 - 1883). A sistematização enquanto ciência se inicia na Alemanha no século XIX com o naturalismo e comparação de paisagens de Alexander Von Humboldt e com a análise natural/histórica da sociedade e seus impactos sobre o meio de Karl Ritter. Neste processo a base positivista se solidificou.

Saltando a um período mais recente, durante a década de 1970, tanto a Geografia Clássica quanto a chamada Nova Geografia (composta pelas vertentes Pragmática, Teorética e Quantitativa), passaram a ser questionadas pela Geografia Crítica no cenário nacional, da qual Santos (1986) é um expoente. Esta nova abordagem, baseada principalmente no materialismo histórico-dialético de Marx, surgiu como alternativa ao focar a desigualdade social na criação do espaço geográfico pelo modo de 
produção capitalista. Os problemas sociais oriundos das intervenções no espaço por meio das novas técnicas produtivas do capitalismo monopolista e financeiro se tornaram objeto de estudo mais profundo.

Para discorrer acerca das trajetórias da Ciência Geográfica e do ensino de Geografia especificamente no Brasil, Cavalcanti (2012, p. 21) afirma que,

A geografia brasileira, seja acadêmica, seja escolar, institucionalizou-se no início do século XX, via Sociedade Brasileira de Geografia (SBG), Instituto Brasileiro de Geografia e Estatística (IBGE), Universidade de São Paulo (USP), e outras instituições, e, assim como em outros países, essa institucionalização está vinculada ao seu ensino.

Para contextualizar a maneira como a trajetória da Geografia escolar (vinculada ao ensino básico) e acadêmica (ensino superior) se cruzam, Cavalcanti (2012, p. 21-23) também aponta que:

[...] a partir de 1980 o denominado 'movimento de renovação da geografia' (da geografia acadêmica, do ensino de geografia) [...] ficou inicialmente marcado pela disputa de hegemonia de dois núcleos principais, um aglutinando uma dita geografia 'tradicional', que se mantinha tal como se havia estruturado nas primeiras décadas do século XX, e outros que representava uma geografia nova, que busca superar a tradicional, que se proclamava 'crítica' com o predomínio de uma orientação marxista.

Por outro lado, no âmbito da Geografia escolar, Cavalcanti (2012) declara que não havia unidade na Geografia Crítica, mas, sim, no máximo "denúncias comuns", que expressavam o descontentamento quanto aos rumos que tomavam as práticas de ensino. A Geografia neste momento falha ao atrair a atenção dos estudantes, ao não transmitir a correta importância ou relevância dos conteúdos expostos. Serve, basicamente, aos projetos políticos de formar um sentimento de patriotismo acrítico e estático.

Na década de 1990, segundo Cavalcanti (2012), surgem novas investigações acerca da Geografia escolar, do ensino de Geografia, havendo aumento de palestras, debates em espaços da Associação de Geógrafos Brasileiros (AGB), artigos em periódicos, todos visando alterar as práticas de ensino de Geografia, por uma Geografia que dialogue com o cotidiano discente.

A nova atenção no entorno da estruturação dos conhecimentos da/na Geografia escolar envolve: os conhecimentos geográficos acadêmicos do professor; a constituição da Geografia escolar quanto às orientações de currículo e plano de ensino; e conhecimentos da matéria, didáticos e pedagógicos. Diante disso, Cavalcanti (2012, p. 24-27) é objetiva ao apontar que apesar dos

[...] caminhos paralelos na produção teórica da geografia acadêmica e da teoria sobre o ensino [...] a geografia escolar tem um estatuto próprio e não necessariamente está 
subordinada ao que se prescreve para ela na Academia [...] a geografia escolar não é uma simplificação da ciência, no sentido de se ter como parâmetro a referência direta do conhecimento científico para o cotidiano dos alunos.

Considerando as colocações acima de que a Geografia escolar não está subordinada à Geografia acadêmica, o que fazer diante da presença das práticas de ensino tradicional de Geografia, observadas durante o estágio de observação em Londrina-PR nos Colégios Estaduais Barão do Rio Branco e Vicente Rijo, já que essa por si mesma não é suficiente para desenvolver uma explicação geográfica para diversos fenômenos presentes na realidade discente?

Para começarmos a traçar uma resposta, deve-se buscar quais são as marcas do mundo em que vivemos, visando a conexão sociedade-educação, para que a atividade didática-pedagógica não sofra da mesma descontextualização tão recorrentemente criticada.

\section{TRAÇOS SOCIAIS COMUNS NO CONTEXTO DA GLOBALIZAÇÃO NO SÉCULO XXI}

De maneira arbitrária, podemos dizer que o mundo atual apresenta, entre tantas, as seguintes marcas profundas: a globalização, as tecnologias da comunicação e da informação, a urbanização e o multiculturalismo.

A globalização é marcada pela homogeneidade e pela heterogeneidade. Isto é, pela padronização de espaços e sociedades, e, pelas desigualdades sociais, conflitos territoriais, violências, entre outros aspectos.

As tecnologias da comunicação e da informação contribuem para promover o acompanhamento dos acontecimentos em tempo real, além de auxiliarem na homogeneização cultural por meio da padronização de gostos, consumo, alimentação e modelos de vida, por exemplo.

As cidades, além de serem os maiores habitats humanos, são os lócus de padronização de aspectos da vida cotidiana, como uso de determinados tipos de transporte, alimentação, vestimentas, manifestações culturais, desigualdades sociais, conflitos etc.

O multiculturalismo, conforme apontado por Cavalcanti (2012, p. 17), é decorrente da “[...] intensificação da convivência entre povos de diferentes lugares do mundo e com diferentes culturas, ocasionada pela maior comunicação entre as pessoas do mundo inteiro [...]”. Ou seja, uma sociedade ainda marcada pela diversidade, apesar das tentativas de padronização.

Além destas marcas, Salecl (2005) destaca o momento em que o indivíduo se encontra atualmente, inserido em uma sociedade que prega a total liberdade de escolha, mas que na verdade restringe o livre desenvolvimento individual, em seu caráter físico, moral e psicológico.

Nessa sociedade altamente individualizada, a ansiedade e a angústia imperam frente ao “excesso de escolhas" e, para proporcionar respostas a elas, o mercado se enche de opções, em 
variados segmentos, para que funcionem como guia a um mundo com crescente ausência de limites, de modo que tudo aparentemente pode ser desejado e venerado, em razão do enfraquecimento das tradicionais formas simbólicas que moldam as relações sociais.

Para Bauman (2011), o verdadeiro segredo de todo sistema social que dure é fazer com que os seus indivíduos desejem realizar aquilo que o sistema precisa, permitindo-o se manter e se reproduzir. Para que exerça uma função essencial, a educação precisa retomar seu papel emancipador, assumindo um caráter sólido frente a esse contexto cada vez mais volátil e de rápido esquecimento.

Neste processo, é preciso reconhecer o consumidor enquanto diferente do cidadão, pois o consumidor só se atenta à atualização técnica, deixando de lado a política, seus acontecimentos e as suas especificidades. Não mais defende as suas liberdades e direitos conquistados, podendo ser facilmente manipulado e dominado através de seu desinteresse político e social gerado pela ignorância e por uma educação cada vez mais distante, desinteressante e controlada pelos poderes heterogêneos globais.

Passa-se da construção do conhecimento concreto e abstrato para o completo esquecimento, cada vez mais rápido. Segundo Bauman (2011), a sociedade moderna atual assume um caráter "líquido", em que o aprendizado perdeu muito do seu conceito original e pragmático, acreditando-se que nada mais é insubstituível ou durará por muito tempo. Nada é feito para ser absorvido ou sobreviver além do programado. Com essa facilidade de mudanças, tudo se torna refém do presente. O sentido de tempo se modifica (BAUMAN, 2011). Não existe a opção de se trabalhar ou se esforçar em uma escolha. Passa-se logo para outra. É a eterna expectativa de se anular o passado e prevenir o futuro, apagando as escolhas erradas e assumindo uma nova realidade, uma nova identidade/personalidade, "uma série infinita de novos começos".

No século XXI, o desenvolvimento abrupto do meio-técnico-científico-informacional, já detalhado por Santos (1996), bem como das instituições e transações financeiras, da velocidade dos transportes, mobilidade e instabilidade das empresas e indústrias por meio de meios produtivos cada vez mais espalhados em rede pelo globo, além do advento das informações instantâneas da internet e outras tecnologias, criaram um novo contexto. É global principalmente para suas desigualdades, isolando as realidades privilegiadas (não por acaso).

O processo educacional não fica isento a estas transformações, obedecendo lógicas mundiais de mercado e perdendo seu caráter emancipador e significativo. Torna-se mais um produto com validade programada, passageiro e maçante, ao alcance das mãos em qualquer dispositivo eletrônico (SERRES, 2013). Acaba por fazer parte, inerentemente, das relações sociais repletas de disputas por poder. Fica excluída a parcela mais vulnerável da população que deveria ser priorizada. 
É preciso acreditar e destacar que neste contexto, o professor tem sua responsabilidade aumentada, precisando adaptar-se e renovar suas práticas, utilizando quando for possível as mesmas tecnologias que com ele rivalizam, mas, principalmente, proporcionando diálogos, discussões, exemplos e construções formais e informais do conhecimento, em conjunto com o estudante e por meio da participação ativa deste. Somente assim é possível vislumbrar a ingressão das discussões sociais mais importantes, numa luta constante por direitos essenciais, entre eles a educação.

Costa e Rocha (2010) destacam a necessidade dos profissionais da Geografia se inserirem e saberem analisar propriamente o espaço de forma atualizada, após diversas transformações. É um desafio aos professores de Geografia, para que consigam associar essa realidade com o cotidiano do estudante, pois ele vive essas transformações diariamente em sua vida, que muitas vezes podem passar despercebidas entre as relações de diferentes escalas (local-global) e entre os interesses hegemônicos políticos e econômicos.

As distâncias podem ter se encurtado (de certa forma), pela velocidade das comunicações e transportes, assim como os centros de poder parecem ter se modificado e se espalhado pelo globo terrestre. Mas não se pode perder de vista a análise crítica de quem pode desfrutar desses avanços, somente alguns poucos privilegiados.

No entanto, é demasiadamente importante não perder de vista que estas novas possibilidades tecnológicas devem ser usadas para promover o bem-estar social e melhorar a qualidade de vida da população. Sem esta premissa corremos o risco da tecnologia servir apenas aos interesses financeiros de restritos e poderosos grupos internacionais. O pensamento crítico deve estar sempre presente para avaliar os custos e os ganhos sociais em questão (COSTA e ROCHA, 2010, p. 41).

A Geografia deve primar pelo desenvolvimento social de forma a utilizar todos os recursos disponíveis em todas as suas escalas e recortes, assim como no trabalho com seus principais conceitos: região, território, lugar e paisagem, e no seu principal objeto de estudo que dá origem a esses conceitos - o espaço. Somente o conceito de espaço não é suficiente para o geógrafo, sendo necessário o raciocínio sobre a ordem espacial dos fenômenos, sua distribuição e as consequências dessa espacialidade. Entretanto, diante dessas necessidades, as práticas tradicionais ainda presentes no ensino de Geografia precisam ser repensadas.

Retomando a presença do ensino geográfico tradicional no estágio de observação e a relação deste com a formação dos futuros docentes de Geografia, cabe mencionar Santos (2013, p. 257) ao dizer que

O saber acadêmico descontextualizado da realidade e das necessidades da escola deixa lacunas que comprometem a formação docente, na qual os futuros docentes de 
Geografia apresentam-se somente como responsáveis por transmitir os conhecimentos geográficos e, muitas vezes chegam à escola como meros reprodutores de um saber alheio.

Baseado nesta afirmação, verificou-se significativo distanciamento dos conteúdos produzidos e debatidos na Geografia acadêmica, na Geografia escolar e a realidade dos estudantes. No estágio de observação, foi verificado intensa presença de atividades relacionadas a decorar estados, capitais, clima e vegetação, além de colorir mapas e realizar cópias do livro didático. Conteúdos abordados sem nenhum nexo com a cotidiano dos estudantes. Conhecer aspectos do território nacional é fundamental, mas aqui a crítica centraliza-se na prática didática-pedagógica escolhida pelos docentes, assim como na abordagem executada.

Cabe discutir, na sequência, qual é a metodologia considerada apropriada para analisar as atividades experienciadas em sala de aula, a partir das quais foi possível traçar a presente linha de argumentação.

\section{ENSINO DE GEOGRAFIA NOS COLÉGIOS ESTADUAIS BARÃO DO RIO BRANCO E VICENTE RIJO - LONDRINA/PR}

Atualmente, de acordo com Katuta (2007, p. 224), predomina um ensino de racionalidade técnica, repetitivo e memorizado, em que “[...] a teoria e a prática, o pensamento e a ação constituemse em atividades que se realizam em separado, não possuindo relações orgânicas entre si”.

Seguindo este raciocínio, Kaercher (2013) admite que alguns pontos ainda ocorrem no ensino de Geografia atual, como: conteúdos complexos que são trabalhados em poucas horas-aulas, se tornando "vencidos", e não ensinados; perda do raciocínio espacial no cotidiano do estudante; repetição de informações; uso do mesmo recurso didático (o livro); medo de inovar; mau uso da lousa; postura estática do professor, sem perceber os conhecimentos já adquiridos pelos estudantes que poderiam ser usados como pontos de reflexão em aula; e dificuldade em rever metodologias que não deram certo (como várias apresentações em grupo no mesmo dia, que resulta em perda de atenção) dentre outros.

O conteúdo é passado como verdade absoluta, sem que o estudante possa questionar ou mesmo seja incentivado a isso. Mapas e suas funcionalidades/construções são pouco utilizados, enquanto o diálogo entre professor e estudantes é empobrecido. Estes últimos podem entender como falta de respeito, agindo da mesma forma. A falta de atualização do professor, como a procura por novos autores, fontes e diferentes abordagens sobre determinado tema, turva os objetivos pedagógicos, aonde se procura ensinar o conteúdo com a finalidade nele e não no desenvolvimento 
de alguma habilidade mais ampla. A sequência de aulas perde o nexo, os conteúdos não dialogam e ocorre a culpabilização dos estudantes quando o conteúdo não é "absorvido".

Comparando os apontamentos de Kaercher (2013) com as experiências que os pesquisadores tiveram durante o período de estágio de observação em aulas de Geografia por meio da disciplina de Ensino de Geografia e Estágio de Vivência Docente pelo $3^{\circ}$ ano de graduação do curso de Geografia na Universidade Estadual de Londrina, nos Colégios Estaduais Barão do Rio Branco e Vicente Rijo, da mesma cidade, pode-se corroborar as afirmações feitas até aqui. Infelizmente estão próximas da realidade do ensino fundamental e médio das escolas públicas brasileiras.

Estas experiências e a análise delas decorrentes, podem ser classificadas como uma metodologia de estudo de caso. Segundo Ventura (2007), toda pesquisa científica necessita definir seu objeto de estudo, construir um processo de investigação e definir como será feito.

Em relação aos estudos de caso, deverá haver sempre a preocupação de perceber o que o caso sugere a respeito do todo e não o estudo apenas de forma isolada. O estudo de caso representa uma investigação empírica amplamente dotada de planejamento, coleta e análise de dados (podendo envolver discussões teóricas e conceituais). Pode ser de caso único ou múltiplos, com enfoque quantitativo ou qualitativo (VENTURA, 2007).

Determinando os dois colégios como objetos de estudo, a análise e discussão posterior às vivências pautarão o alcance dos métodos de ensino aqui detalhados ao ensino regular dentro da esfera pública brasileira, resguardando as devidas proporções do imenso território nacional.

Dessa maneira, cabe caracterizar o estudo como de cunho qualitativo, em que foram 11 dias frequentando o Colégio Estadual Barão do Rio Branco, em um total de 25 aulas divididas entre três turmas de $7^{\circ}$ ano do ensino fundamental; e 10 dias no Colégio Estadual Vicente Rijo, durante 27 aulas divididas entre uma turma de $6^{\circ}$ ano do ensino fundamental e três turmas de $2^{\circ}$ ano do ensino médio. Cada turma possuía cerca de 30 estudantes. Na sala de aula, os pesquisadores participaram enquanto “observador total", isto é, postura em o pesquisador não interage com o grupo observado e desenvolve sua pesquisa estando na presença de um grupo sem estabelecer relações interpessoais (LÜDKE; ANDRÉ, 1986). No caso, não foram estabelecidas relações interpessoais com os estudantes nas aulas destinadas para observação. O foco de observação foram as metodologias e atividades propostas pelos professores, observados ao longo dos dias de estágio. Os pesquisadores realizaram registros em caderneta. Os métodos utilizados em sala de aula para o ensino de conteúdos diversos como relevo; hidrografia; clima; blocos econômicos; globalização; e redes mundiais, foram praticamente os mesmos, para estudantes que variavam de idade entre 12 e 16 anos. 


\section{RESULTADOS E DISCUSSÃO}

Os resultados aferidos foram por meio de metodologias e atividades propostas pelos professores, observadas e analisadas ao longo dos dias de estágio.

Alguns dos pontos que mais chamaram a atenção, principalmente pela precariedade, estão representados na Figura 1. De maneira geral, não foram apresentados outros recursos além do livro didático, nem mesmo segurança para a construção do conhecimento. Os exercícios se resumiam a trechos e parágrafos dos livros que os estudantes deveriam copiar, e as provas orais possuíam como único objetivo a memorização de informações, sem qualquer explicação ou diálogo sobre o porquê de tal atividade.

Figura 1 - Atividades observadas durante estágio de vivência docente nos Colégios Estaduais Barão do Rio Branco e Vicente Rijo em Londrina/PR - 2015.

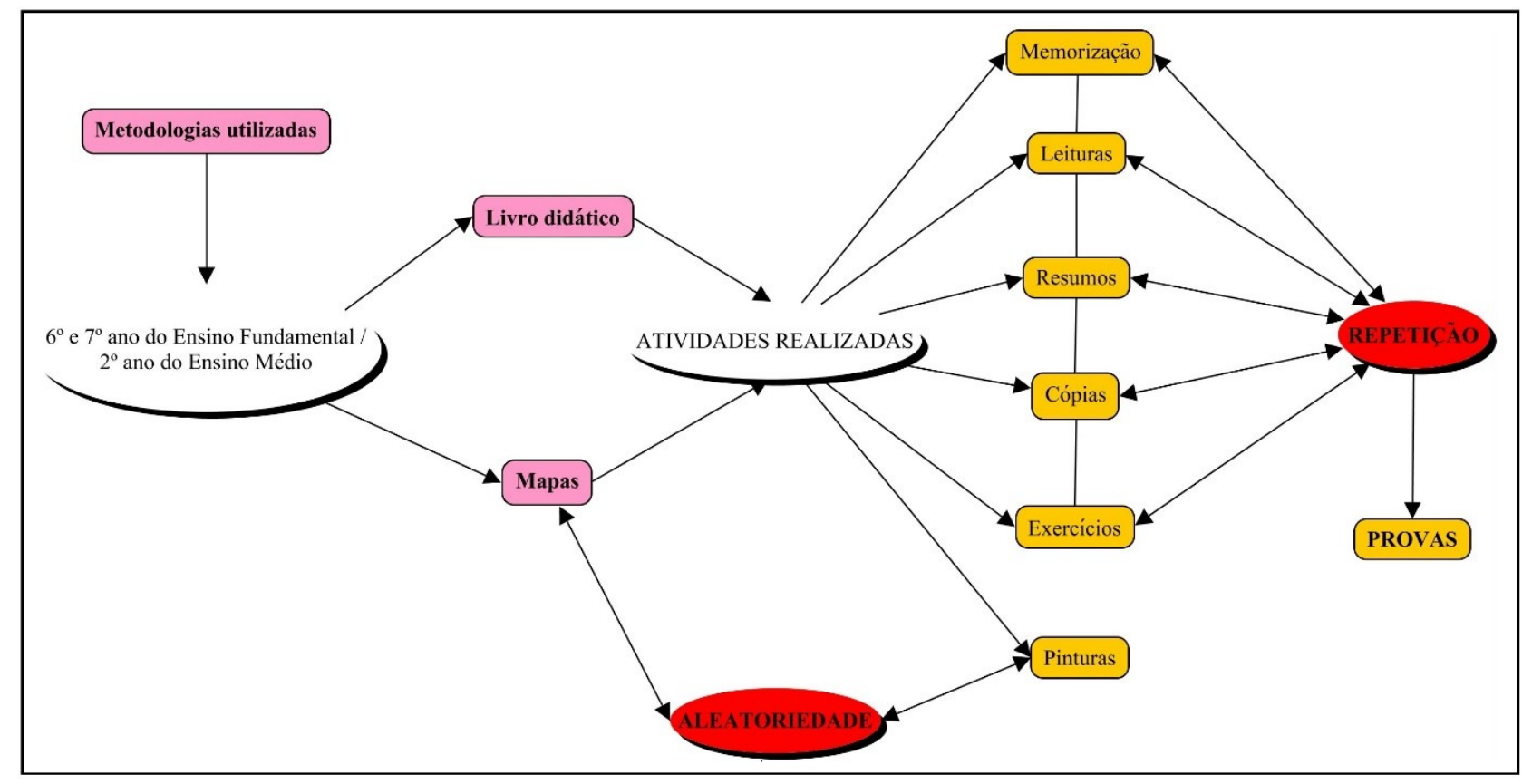

Fonte: os autores (2018).

O único contato com mapas foi para realizar pinturas sem qualquer ordem cartográfica por parte dos elementos presentes. Outros pontos preocupantes foram observados, como: diferentes informações/conteúdos passados em diferentes turmas de mesmo ano, chegando até em erros consideráveis na veracidade destes; divagação sobre a temática que está sendo trabalhada; desavenças particulares com alguns estudantes; exposição de opiniões particulares político-partidárias, assim como informações sem fontes verificáveis ou confiáveis; e apresentações de trabalhos com pouco ou nenhum valor educativo, pois não existiu uma interação por parte do professor sobre o que foi apresentado ou comentário relevante. 
Portanto, após a exposição de tantos itens preocupantes, obteve-se a conclusão que somente duas atividades saíram da rotina maçante, repetitiva e distanciada das aulas de Geografia que foram presenciadas: a elaboração de um teatro para representação de tipos de relevo e como as massas de ar se comportam na ocorrência de chuvas orográficas; e a confecção de um desenho sobre a mesma temática, mas de forma livre, para que cada estudante representasse com os elementos que considerasse melhor.

Feitas as observações referentes à rotina das aulas, podemos considerar que o ensino público em Geografia segue uma linha ainda com muitos traços do tradicional, em diferentes séries, para diferentes idades e em diferentes colégios. Percebe-se um ciclo vicioso, em que a aula é ministrada de maneira desinteressante, os estudantes não se veem contemplados pelo conteúdo (e possuem poucas possibilidades de abertura para participação em aula) e acabam por agir muitas vezes de maneira desrespeitosa.

A pressão do ensino tradicional faz com que as aulas, não só de Geografia, permaneçam desinteressantes, com a qualidade de ensino comprometida, formando sujeitos para a vida adulta com sérios problemas de interpretação e raciocínio. É indispensável lembrar que a abordagem tradicional também possui contribuições e pode ser utilizada na sala de aula. Entretanto, é necessário que o professor planeje, pense e argumente visando inserir o estudante enquanto participante ativo deste processo.

Apesar de todas as dificuldades e do distanciamento entre as experiências que os futuros professores obtêm na graduação em comparação com o que encontrarão em sala de aula (dicotomia ensino superior-básico), o aprimoramento, a pesquisa e a busca por novos métodos de ensino e didáticas são necessárias para qualquer docente que se julgue realizando um ensino crítico em Geografia.

São necessárias novas formas que melhorem a aprendizagem, que transformem o conhecimento em algo poderoso para a formação do indivíduo e para que os estudantes sejam mais ativos neste processo. Para que se sintam mais próximos do conteúdo em sua realidade cotidiana e possam realmente desenvolver o pensamento crítico, atuando sobre a realidade desigual que os cerca e melhorando-a. Os caminhos que contribuem para novos métodos de ensino e didática serão debatidos mais adiante no texto.

O ensino tradicional em Geografia, de um lado, não está errado, mas por outro não consegue desenvolver uma leitura geográfica condizente com a realidade discente, ainda mais em um contexto de globalização. A aceleração mundial no ritmo do trabalho e consumo, guiada pela intensa produção de mercadorias, influencia para que o ensino se estruture no mesmo molde de produtividade, para o 
qual as práticas pedagógicas conservadoras não ajudam elucidar. Segundo as colocações de Fonseca e Torres (2013, p. 57),

O ensino de Geografia tradicional não consegue espaço na escola do século XXI; ou ela se transforma radicalmente e prova que pode colaborar na formação de cidadãos ativos para levar o aluno a entender o mundo em que vivemos, capacitando-o na compreensão das relações complexas existentes entre a sociedade e a natureza.

Diante disso, é primordial que se discutam alternativas à prática pedagógica hoje exercida, que devido às condições básicas de trabalho precárias, encontra-se degradada e invariavelmente descontextualizada. Dentro desse processo, um dos principais desafios se encontra em como quebrar esse ciclo repetitivo e vicioso já estabelecido.

Ao tentar romper (ou fragilizar) o ciclo de reprodução massivo das práticas pedagógicas tradicionais de ensino em Geografia nas escolas e possibilitar que o estudante realize uma leitura geográfica do mundo por meio de seu cotidiano, alguns pontos devem ser considerados. São eles: as instâncias burocrática e administrativa que impõe a prioridade de cumprir o calendário escolar e os conteúdos instituídos; o período de formação acadêmica dos professores e a possibilidade de uma formação continuada; e as práticas didáticas, teóricas e metodológicas.

No momento atual, almeja-se uma nova realidade que atravesse obrigatoriamente uma fase de transição (já em vigor em alguns casos e locais isolados), na qual

[...] centram-se na concepção da formação como um processo permanente, marcado pelo desenvolvimento da capacidade reflexiva, crítica e criativa, conferindo ao professor autonomia na profissão e elevando seu estatuto profissional (PONTUSCHKA, PAGANELLI e CACETE, 2009, p. 92).

Deve-se levar em conta um novo projeto pedagógico para que essa mudança atinja cada vez maior profundidade. Nele, se leva em conta três princípios básicos: a competência para orientar o conhecimento teórico em ações práticas e pedagógica, a coerência entre a relação teoria-prática e a pesquisa como elemento essencial na formação do docente.

No caso específico da pesquisa, esta irá proporcionar o aprofundamento necessário para que o professor tenha uma gama de opções metodológicas e uma diversidade de concepções teóricas e filosóficas, influenciando na construção do pensamento crítico de seus estudantes. Podem então compreender a realidade por diversas abordagens e consequentemente atuar sobre ela e modificá-la frente as várias necessidades sociais do mundo globalizado.

Foquemos agora em dois pontos mencionados anteriormente, que são considerados de elevada importância para a compreensão do alcance que as mudanças devem atingir, assim como das 
possibilidades de sua implantação efetiva: o período de formação acadêmica dos professores e a formação continuada.

Alguns daqueles que exercem o ensino de Geografia pelo viés tradicional não o fazem "malintencionados", mas sim enquanto forma de conhecimento apreendido no momento de sua formação acadêmica. Devemos nos lembrar da variedade de faixas etárias da classe docente. Mas, uma sintonia, e não subordinação, com as mudanças da sociedade e saberes acadêmicos é indispensável.

Uma forma coerente de atualização para a docência seria a formação continuada por meio dos cursos de pós-graduação lato sensu (especialização) e stricto sensu (mestrado, doutorado e pósdoutorado). Aliado a isso, um maior engajamento das pesquisas em educação com a realidade escolar brasileira é necessário. Estes estudos podem não somente considerar as práticas vigentes e analisálas, mas buscar e propor alternativas para a materialização do ensino crítico. Não podemos esquecer, conforme apontado por Tomita (2012, p. 44) acerca da formação docente que, “[...] é notória a participação cada vez mais intensa nos congressos, seminários, cursos de atualização, semana pedagógica e outros, que oferecem condição para o sustento e a segurança na sua nova maneira de proceder o ensino".

Porém, qual seria a proporção desta ascendência participativa dentro de um quadro geral, em que se misturam diferentes escalas territoriais e realidades vividas? A prática docente envolve alteração constante, inclusive alterando seu próprio processo de formação.

Somados a esses questionamentos, não se pode mascarar as falhas dentro da formação acadêmica. Por exemplo, dois anos com enfoque na licenciatura, inclusos em cursos de graduação de maior duração, seriam suficientes para a formação docente? Ou talvez o segredo estaria nas instâncias burocráticas e administrativas? Nos debates acalorados que envolvem as grades curriculares e os programas disciplinares? Em ampliar o tempo de formação teórico-metodológica, em conjunto com os estágios de observação e regência?

São inúmeras possibilidades e questões a serem debatidas e o que emerge com mais urgência é que justamente não se evitem tais discussões. Como docentes e profissionais da Ciência Geográfica, são contendas que inerentemente nos cercam ao longo de uma formação que nunca se completa totalmente. Vale lembrar Cavalcanti $(2012$, p. 30) ao escrever, que

[...] no âmbito da geografia acadêmica ligada ao ensino houve significativos avanços, que podem ser pontuados da seguinte maneira: em primeiro lugar, o número de trabalhos nessa área tem aumentado bastante nos últimos anos e eles tem-se constituído em ricos diagnósticos da geografia ensinada e produzida no país, fornecendo parâmetros para avaliação de propostas curriculares, de políticas educacionais, de livros didáticos, de metodologias e de procedimentos empregados no ensino [...]; em segundo lugar, pode-se já apostar num processo inicial de 
reconhecimento da legitimidade e da relevância da pesquisa no ensino de geografia realizada pela comunidade acadêmica.

A importância da formação continuada está principalmente em compreender as transformações ocorridas no espaço geográfico por meio do desenvolvimento das técnicas e atores sociais e atualizar essas formas de representação de acordo com a linguagem geográfica. Cada vez mais se perde a noção da linguagem exposta pelos estudantes em sala de aula - de seu conhecimento prévio - e o ensino geralmente se apresenta distanciado e frio, disposto a formar indivíduos descaracterizados de seu meio social, (re)construído ao seu redor pelos que tem poder e entendimento para tal. E também aos que interessam que a aprendizagem permaneça dessa forma.

Dessa maneira, verifica-se a necessidade da interação dialética entre as representações e linguagens utilizadas cotidianamente pelos alunos com aquelas disseminadas pela escola. É por meio desta interação que ocorre a (re)construção de conhecimentos, representações e linguagens do sujeito cognoscente que deve ser compreendido em sua dimensão triádica (KATUTA, 2007, p. 227).

Esta interação pode ser estimulada, por exemplo, pela iniciativa da universidade em aproximar o futuro professor da escola. Porém, pouco contato se tem com esse caráter relevante da linguagem durante os cursos de formação de professores, sendo necessário que o docente vá em busca desse conhecimento posteriormente, em sua formação continuada. Mas, para que essa busca seja proveitosa, é necessário que o profissional de ensino valorize a pesquisa investigativa em busca de novas abordagens e adote a reflexão crítica acerca de sua prática docente, pesando o que pode ser melhorado, modificado ou atualizado. Como afirma Chimentão (2009), pode ser resumida como uma atualização e aperfeiçoamento dos saberes docentes em comparação com a afirmação inicial, frente às novas necessidades do mundo globalizado e da sociedade nele presente.

A nosso ver, a formação continuada passa a ser um dos pré-requisitos básicos para a transformação do professor, pois é através do estudo, da pesquisa, da reflexão, do constante contato com novas concepções, proporcionado pelos programas de formação continuada, que é possível a mudança. Fica mais difícil de o professor mudar seu modo de pensar o fazer pedagógico se ele não tiver a oportunidade de vivenciar novas experiências, novas pesquisas, novas formas de ver e pensar a escola (CHIMENTAO, 2009, p. 3).

Entretanto, segundo Nascimento (2000), as propostas de capacitação dos docentes têm apresentado baixa eficácia e algumas das razões apontadas são: a desvinculação entre teoria e prática, a ênfase excessiva em aspectos normativos, a falta de projetos coletivos e/ou institucionais dentre outros. É preciso ressaltar que a diversidade existente entre um grupo de professores, como os da rede 
estadual de ensino do Paraná, por exemplo, obstaculiza que a formação continuada atinja todas e todos simultaneamente, nas mesmas proporções.

Candau (1997) apresenta três aspectos fundamentais em um processo para a verdadeira formação continuada de professores: a escola, como lócus privilegiado de formação; a valorização do saber docente; e o ciclo de vida dos professores. Partindo da necessidade presente no dia-a-dia do ambiente de trabalho do professor (reflexo das necessidades da própria sociedade), na importância do seu conhecimento já adquirido e de suas experiências.

Embora a formação continuada deva atender às necessidades do professor no seu cotidiano, ela não pode ser entendida como um receituário, ou seja, um conjunto de modelos metodológicos e/ou lista de conteúdos que, se seguidos, serão a solução para os problemas. Os processos de formação continuada podem ser valiosíssimos, se conseguirem aproximar os pressupostos teóricos e a prática pedagógica. A formação continuada deve ser capaz de conscientizar o professor de que teoria e prática são "dois lados da mesma moeda", que a teoria o ajuda a compreender melhor a sua prática e a lhe dar sentido e, conseqüentemente, que a prática proporciona melhor entendimento da teoria ou, ainda, revela a necessidade de nela fundamentarse (CHIMENTAO, 2009, p. 5).

A importância do diálogo entre teoria e prática é fundamental, e não se pode cometer o erro de considerar que apenas a reflexão sobre a prática é o suficiente para se resolver os problemas do ensino tradicional atual. Segundo Chimentão (2009), resumidamente, deve-se objetivar a competência na profissão, a partir dos recursos existentes.

Uma formação teórica consistente e a consciência acerca dos aspectos que melhor podem funcionar na prática cotidiana em sala de aula nos leva até a segunda intersecção em nossa discussão: das ações didáticas, teóricas e metodológicas.

Em relação à Geografia, Tomita (2012) faz refletir sobre o ensino, em que a preocupação deve repousar sobre a base teórico-metodológica, modelando-a por meio da investigação do modo como se ensina (e como se aprende), partindo da seleção e do tratamento dos conteúdos programáticos, da utilização dos recursos técnicos e materiais, da estratégia de ensino e da avaliação. Neste processo, o arcabouço de referenciais teóricos deverá permear todo o ensino de Geografia.

Porém, neste momento, são as contribuições de Cavalcanti (2012, p. 36-37), que mais nos lembram das práticas verificadas durante o referido estágio de observação:

Na prática, a geografia ensinada não consegue, muitas vezes, ultrapassar e superar as descrições e as enumerações de dados e fenômenos, como é tradição dessa disciplina. Nessas condições, o livro didático, muitas vezes trazendo um conteúdo padronizado, define o que vai ensinar, e os professores tratam os temas em si mesmos, sem permitir que sua abordagem sirva para transitar na escala global-local, tendo como foco o local. 
Como evitar estas ações? Algumas alternativas, que poderiam ser melhor consideradas, envolvem colocar o estudante como centro e sujeito do processo de ensino, considerando sua experiência cotidiana no processo de aprendizagem. Ter o pleno domínio de conteúdo e trabalhar com situações-problema, para a formação de um pensamento conceitual que considere as diferentes escalas e dimensões do conhecimento. Também considerar a Geografia enquanto ciência complexa para a vida, em que os conhecimentos geográficos são fundamentais para interpretar as leituras acerca de diferentes partes do globo.

Ainda segundo Kaercher (2013), deve-se fomentar a dúvida entre os estudantes, um raciocínio crítico, para que estes possam construir o conhecimento a partir do que já está formado historicamente e paralelamente ao conhecimento que já possuem. Dessa forma, almeja-se uma evolução tanto científica quanto nos conhecimentos cotidianos, que se cruzam. Não é necessário somente um bom domínio do conteúdo e das informações, mas é preciso que o professor saiba como abordar a importância da ciência para a compreensão do mundo em que o estudante vive.

Esse autor leva a discussão adiante e afirma que além de ensinar seu conteúdo específico, um professor de Geografia deve ajudar (assim como toda a escola) na formação cidadã do estudante, o que engloba respeito, consciência crítica e capacidade de ação em seu contexto social.

Ou seja, é preciso formar uma consciência espacial para a prática da cidadania. Consciência espacial como sinônimo de perceber o espaço como um elemento importante de nossa organização social, presente em nosso cotidiano (KAERCHER, 2013, p. 225).

Esta consciência espacial engloba uma busca pela autonomia do indivíduo, em que a compreensão acerca da formação espacial a sua volta propicia ferramentas de ação e transformação sobre as suas diversas particularidades. E no almejo de atividades que propiciem ao estudante uma verdadeira leitura geográfica do meio, recorre-se às palavras de Freire (1996, p. 123):

O desrespeito à leitura de mundo do educando revela o gosto elitista, portanto antidemocrático, do educador que, desta forma, não escutando o educando, com ele não fala. Nele deposita seus comunicados. Há algo ainda de real importância a ser discutido na reflexão sobre a recusa ou respeito à leitura de mundo do educando por parte do educador. A leitura de mundo revela, evidentemente, a inteligência do mundo que vem cultural e socialmente se constituindo. Revela também o trabalho individual de cada sujeito no próprio processo de assimilação da inteligência do mundo.

Faz-se preciso partir da escola - do que é construído em sala de aula pelos estudantes e em conjunto a eles - e a partir daí direcionar ao conteúdo social e historicamente construído, já 
estabelecido. Do particular ao geral, por meio de abstrações e sempre valorizando o papel da linguagem neste processo. A relevância da interação dialética entre as diferentes linguagens presentes em sala de aula se constitui na melhor forma de compreender as diferentes realidades, e mais importante, para que o formando compreenda a sua própria.

Consideram-se estes os principais objetivos a serem buscados pelos professores em sua prática docente, utilizando as especificidades da Ciência Geográfica como instrumentos de construção ativa do conhecimento. São inúmeras as formas de colocá-los em prática, sendo essencial a continuidade das jornadas de discussão desta temática inadiável.

\section{CONSIDERAÇÕES FINAIS}

Após os apontamentos levantados anteriormente nos tópicos norteadores, pretendeu-se neste trabalho demonstrar como a Geografia escolar e a Geografia acadêmica, ambas com suas especificidades, não devem caminhar de forma desconexa. Justamente o que foi verificado durante as práticas de ensino de Geografia nos Colégios Estaduais Barão do Rio Branco e Vicente Rijo em Londrina/PR.

Foram constatadas atividades em sala de aula que não correspondem ao objetivo proposto de uma compreensão holista dos temas. Não houve o fomento de raciocínio crítico nos processos de ensino e de aprendizagem, e nem o debate entre conceitos teóricos e suas formas e conteúdos cotidianos. Muito menos a amplitude no leque de opções didáticas foi suficiente para que se almejassem/sinalizassem mudanças na postura docente.

Aspectos da sociedade e do atual sistema vigente no mundo clamam por diferentes abordagens que transformem a prática pedagógica em algo realmente significativo para o estudante e sua realidade. Algo que possibilite a aquisição de ferramentas com as quais se poderá construir melhores condições de vida e acesso a direitos básicos. Dentro da instabilidade e liquidez do cotidiano, a educação mais do que nunca deve utilizar as ferramentas ao seu alcance, principalmente as tecnológicas, para fortalecer o ensino com a maior solidez possível.

O mundo continua mudando em diferentes ritmos, e, consequentemente, o professor precisa estar em constante atualização de suas referências teóricas, práticas e metodológicas. Faz-se importante ressaltar que essa construção deve ser feita a partir da sala de aula e da formação acadêmica, tendo a prática docente como palco principal de ações. Mas, deve-se considerar também o embasamento teórico, encaixando prática e teoria como duas facetas da mesma abordagem. Para isso, a formação continuada do professor e sua atualização constante são essenciais. 
O conhecimento é construído no movimento do particular para o geral, e de volta do geral ao particular, considerando múltiplas escalas de análise. Assim, torna-se mais completo e abrangente - sendo melhor apreendido pelo estudante, por se tratar da sua realidade particular - e de melhor execução pelo professor, por conseguir atingir e sensibilizar o indivíduo por meio de experiências com intenso significado. Dessa forma, é possível garantir um caminhar simultâneo da construção do conhecimento e do processo de formação docente, envolvendo as práticas didáticas, teóricas e metodológicas em torno da Ciência Geográfica.

Finalmente, este artigo teve um caráter eminentemente provocativo e, a partir disso, outras pesquisas poderão ser realizadas a fim de aprofundar tão importante discussão.

\section{REFERÊNCIAS}

BAUMAN, Z. Vida apressada, ou desafios líquidos modernos para a educação. In: BAUMAN, Z. A ética é possível num mundo de consumidores? Rio de Janeiro: Zahar, 2011.

CANDAU, V. M. F. Formação continuada de professores: tendências atuais. In: CANDAU, V. M. (Org.). Magistério: construção cotidiana. Petrópolis: Vozes, 1997.

CAVALCANTI, L. S. A Geografia escolar e a cidade. 3. ed. Campinas: Papirus, 2012.

CHIMENTAO, L. K. O significado da formação continuada docente. Anais do $4^{\circ}$ Congresso Norte Paranaense de Educação Física Escolar, Londrina, 2009. Disponível em: http://www.uel.br/eventos/conpef/conpef4/trabalhos/comunicacaooralartigo/artigocomoral2.pdf.

Acesso em: 20 jun. 2016.

COSTA, F. R.; ROCHA, M. M. Geografia: Conceitos e Paradigmas - Apontamentos Preliminares. GEOMAE, Campo Mourão, v. 1, n. 2, p. 25-56. 2010. Disponível em: http://www.fecilcam.br/revista/index.php/geomae/article/view/12. Acesso em: 29 jun. 2016.

FONSECA, R. L.; TORRES, E. C. Inclusão, cultura e diversidade: um olhar pela Geografia. In: MOURA, J. D. P; AGUIAR, M. M; HIRATA, C. A. (Orgs.). Práticas em educação socioambiental. Londrina: EdUEL, 2013.

FREIRE, P. Pedagogia da autonomia: saberes necessários à prática educativa. São Paulo: Paz e Terra, 1996.

KAERCHER, N. A. O gato comeu a Geografia Crítica? Alguns obstáculos a superar no ensinoaprendizagem de Geografia. In: PONTUSCHKA, N. N.; OLIVEIRA, A. U. (Orgs.). Geografia em perspectiva: ensino e pesquisa. 4. ed. São Paulo: Contexto, 2013.

KATUTA, A. M. A educação docente: (re)pensando as suas práticas e linguagens. Terra Livre: Presidente Prudente, v. 1, n. 28. p. 221-238. 2007. Disponível em: http://www.agb.org.br/publicacoes/index.php/terralivre/article/view/231/0. Acesso em: 15 jul. 2016.

MELO, A. A.; VLACH, V. R. F.; SAMPAIO, A. C. F. História da Geografia escolar brasileira: continuando a discussão. Anais do V Congresso Luso-Brasileiro de História da Educação, Uberlândia, 2007.

NASCIMENTO, M. G. A formação continuada dos professores: modelos, dimensões e problemática. Ciclo de Conferências da Constituinte Escolar. Caderno Temático, Belo Horizonte, n. 5 , jun., 2000. 
PONTUSCHKA, N. N.; PAGANELLI, T. I.; CACETE, N. H. A formação docente e o ensino superior. In: PONTUSCHKA, N. N.; PAGANELLI, T. I.; CACETE, N. H. Para ensinar e aprender Geografia. 3. ed. São Paulo: Cortez, 2009.

SALECL, R. Sobre a felicidade: ansiedade e consumo na era do hipercapitalismo. São Paulo: Alameda, 2005.

SANTOS, M. Por uma Geografia nova: da crítica da Geografia a uma Geografia crítica. 3. ed. São Paulo: Hucitec, 1986.

SANTOS, M. A natureza do espaço. Técnica e Tempo, Razão e Emoção. São Paulo: Hucitec, 1996.

SANTOS, M. F. P. A relação teoria-prática no estágio supervisionado em Geografia. In: CASTROGIOVANNI, A. C; TONINI, I. M; KAERCHER, N. A. (Orgs). Movimentos no ensinar Geografia. Porto Alegre: Imprensa Livre e Compasso, 2013.

SERRES, M. Polegarzinha. Rio de Janeiro: Bertrand Brasil, 2013.

TOMITA, L. M. S. Os desafios de aprender e ensinar Geografia. In: ASARI, A. Y; MOURA, J. D, P; LIMA, R, M. (Orgs). Múltiplas Geografias. v. 3. Londrina: EdUEL, 2012.

VENTURA, M. M. O estudo de caso como modalidade de pesquisa. SOCERJ, Rio de Janeiro, v. 20, n. 5, p. 383-386, 2007. Disponível em: http://sociedades.cardiol.br/socerj/revista/2007_05/a2007_v20_n05_art10.pdf. Acesso em: $21 \mathrm{dez}$. 2016. 